\section{Leser-Trélat sign as a rare manifestation of cutaneous melanoma}

\author{
Niccolò Gori, Ilaria Esposito, \\ Laura Del Regno, Alessandra D'Amore, \\ Ketty Peris, Alessandro Di Stefani
}

Fondazione Policlinico Universitario A. Gemelli IRCCS, UOC di Dermatologia, Rome; Università Cattolica del Sacro Cuore, Dermatologia, Rome, Italy

\begin{abstract}
Leser-Trélat Sign (LTS) is a rare paraneoplastic syndrome characterized by the sudden eruption of multiple seborrheic keratoses in patients with internal malignancy, commonly localized in the gastrointestinal tract. We report an 80-year-old female patient showing a rapid increase in the number and size of seborrheic keratosis associated with the diagnosis of a cutaneous nodular melanoma (Breslow thickness: 4.5 $\mathrm{mm}$ ) located on the right flank. After the excision of melanoma, subsequent staging procedures resulted negative, moreover no evidence of melanoma recurrence and no changes of the seborrheic keratoses was detected after a follow-up of 52 months. Although the association between melanoma and Leser Trelat sign is rare, an accurate skin examination with the aid of dermatoscopy searching for undiagnosed skin cancers, should be suggested in patient with sudden eruption of keratosis seborrheic to early diagnose and treat a possible melanoma.
\end{abstract}

\section{Introduction}

Leser-Trélat Sign (LTS) is a rare paraneoplastic syndrome characterized by the sudden eruption of multiple seborrheic keratoses in patients with internal malignancy, commonly localized in the gastrointestinal tract. $^{1-3}$

We report one patient with a rapid increase in the number and size of seborrheic keratosis, associated with the development of a cutaneous melanoma.

\section{Clinical Case}

An 80-year-old female was examined for the treatment of multiple, itchy verrucous papules and plaques located on the trunk, which had rapidly increased in number and size during the last year. Physical examination showed hundreds of seborrheic keratoses, with variegated colours ranging from yellowish to brown, located on neck, face, upper chest and back (Figure 1a). In addition, a brown to red plaque with an overlying red pink nodule was observed on the right flank (Figure 1b). The patient was otherwise asymptomatic and in good general health. Dermatoscopy of the lesion on the right flank showed a polymorphous vascular pattern and white streaks at the periphery of the plaque, and irregular blotches of pigmentation and atypical vessels as features of the nodular area (Figure 1c). Histological examination of the excised lesion showed irregular nests of atypical melanocytes located in the dermis with the presence of focal intraepidermal spreading, leading to the diagnosis of invasive melanoma (Breslow thickness: $4.5 \mathrm{~mm}$ ) (Figure 1d). Subsequent staging procedures including sentinel lymph node biopsy, total body CT scan, tumour markers (CEA, CA 19.9, CA 15.3), mammography, Pap smear, gastroscopy and colonoscopy were all negative. After a follow-up of 52 months, no evidence of melanoma recurrence and no changes of the seborrheic keratoses was detected.

\section{Discussion}

LTS was initially described in the 1800 s by Leser and Trélat as a cutaneous sign associated with the onset of multiple eruptive cherry angiomas in oncologic patients, and subsequently by Hollander as associated with seborrheic keratoses in 1900. ${ }^{1-3}$ The lesions are often pruritic and are preferentially located on the trunk with a "Christmas tree" or "rain drop" pattern. ${ }^{1-3}$ LTS is more common in elderly people, with an average age of 61 years and no sex prevalence, and in approximately half of the cases it is associated with adenocarcinomas (gastrointestinal in $32 \%$ ) followed by lymphoproliferative disorders in $20 \%$ and more rarely with breast, lung, bladder, kidney, prostate, ovary or nasopharyngeal carcinoma. ${ }^{3}$ Pathogenesis of the LTS is still unclear, although a correlation between the release of EGF and TGF-alpha from malignant cells and keratinocye proliferation has been proposed. ${ }^{2,3}$ Since the presence of numerous seborrheic keratoses is a common finding in elderly individuals who have, at the same time, a high prevalence of malignancies, some authors questioned the existence of LTS as an entity per se. ${ }^{3}$ However, the finding of the LTS also in young oncologic
Correspondence: Alessandro Di Stefani, Institute of Dermatology, Catholic University of Rome, Fondazione Policlinico Universitario A. Gemelli IRCCS

Largo Agostino Gemelli, 800168 Rome, Italy Tel.: +39 06-30154227

E-mail: alessandro.distefani@gmail.com

Key words: Leser-Trélat sign; melanoma; oncologic patient; paraneoplastic syndrome; seborrheic keratosis.

Conflict of interest: The authors declare no potential conflict of interests.

Received for publication: 11 June 2020.

Accepted for publication: 20 June 2020.

This work is licensed under a Creative Commons Attribution-NonCommercial 4.0 International License (CC BY-NC 4.0).

C Copyright: the Author(s), 2020

Licensee PAGEPress, Italy

Dermatology Reports 2020; 12:8665

doi:10.4081/dr.2020.8665

patients, and its association in more than $20 \%$ of cases with other cutaneous paraneoplastic syndromes as acanthosis nigricans, support the reliability of this condition as a marker of malignancies. ${ }^{3}$

The patient we described is, to our knowledge, the fifth case-report of LTS associated with cutaneous melanoma (Table 1). Diagnosis of nodular melanoma in our patient was made accidentally when the patient come to the outpatient clinic requiring treatment of seborrheic keratoses.

In 1987, Ellis and coworkers, ${ }^{4}$ described the first case of LTS in a 54-yearold man displaying multiple seborrheic keratoses on the upper chest and back, acanthosis nigricans and acrochordons of inguinal, axillary folds and neck, concomitant to a $0.75 \mathrm{~mm}$ thick superficial spreading melanoma of the back. The authors also demonstrated that EGF-receptor expression was initially increased in specimens of seborrheic keratosis and acanthosis nigricans, but decreased after melanoma resection. ${ }^{4}$ Moreover, the level of TGF-alpha in patient's urine also declined markedly after surgery, suggesting the probable etiopathogenetic role of growth factors released from the neoplastic melanocytes. ${ }^{4}$

A second case of LTS associated to a nodular melanoma (Breslow thickness: 2.16 $\mathrm{mm}$ ) with regional lymph node involvement was reported in a 69-year-old man displaying a typical Christmas-tree pattern. ${ }^{5}$ Recently, the occurrence of LTS has been described in a 82-year-old male with multiple melanoma metastasis, in whom the 
occult primary melanoma was supposed to be a pigmented lesion of right ear treated with curettage without histological examination. ${ }^{6}$ A further association of LTS with a metastatic melanoma of unknown primary was reported in a 71-years-old women as the onset of maculopapular lesions of violet-brown colour, pruritic, located on the right posterior thoracic region diagnosed clinically as seborrheic keratosis.? However, in such patient those lesions seem to be disposed in a dermatomeric fashion and do not exhibit the typical clinical hyperkeratotic surface and stuck on waxy aspect, ${ }^{2,7}$ thus in our view, the lesions should be more likely reinterpreted as zosteriform skin metastasis from melanoma. ${ }^{8}$

In this brief literature review of melanoma-associated LTS, the median age of patients (71 years-old, 3 males and 2 females) is in line with previous data of LTS with internal malignancy. ${ }^{3}$ Remarkably, median Breslow thickness resulted 2.45 $\mathrm{mm}$, two cases were of unknown primary
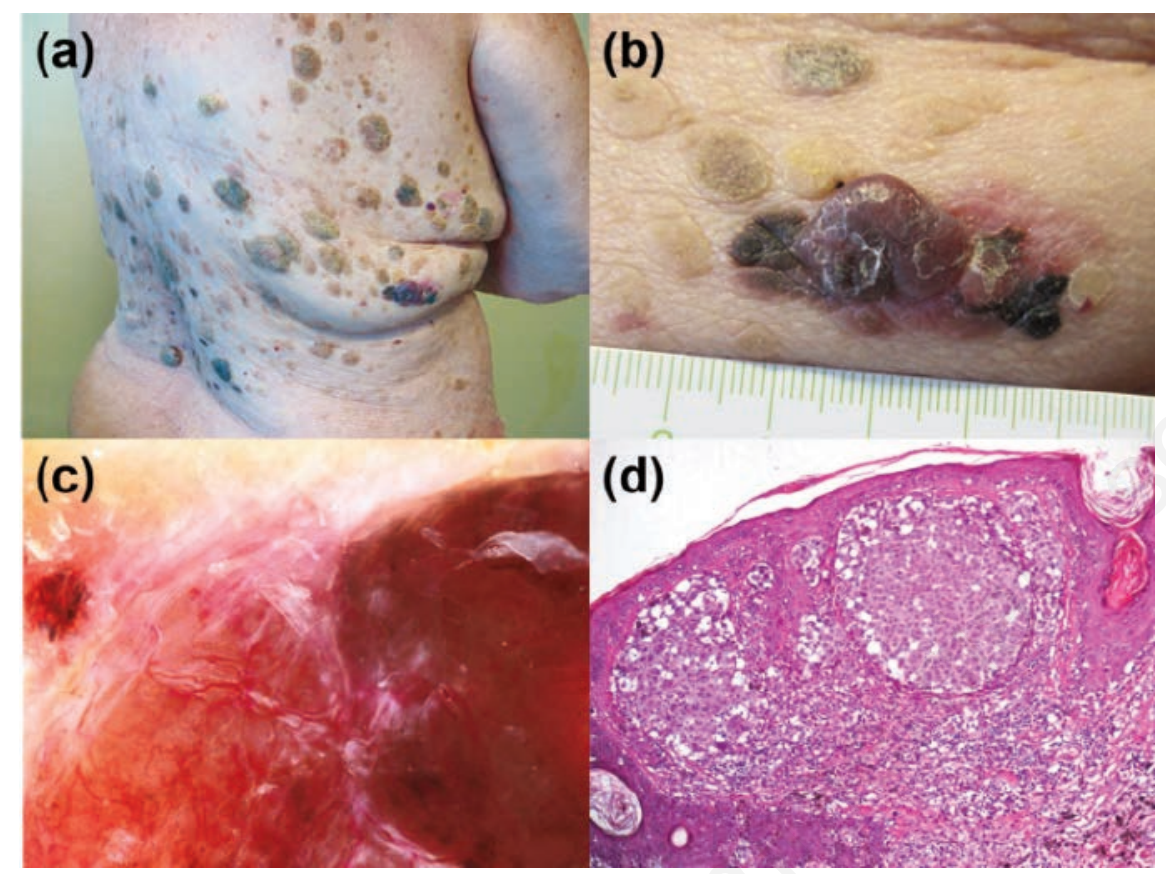

Figure 1. a) Multiple seborrheic keratoses with a Christmas tree pattern located on the trunk of 80 years-old women. b) Clinical detail of a nodular lesion on the right flank partly pigmented and intermingled between seborrheic keratoses. c) Dermatoscopy disclosing polymorphous vessels and irregular blotches. d) Histology showing a detail of the invasive melanoma and seborrheic keratosis-like features of the epidermis. (Hematoxylin and eosin stain; original magnification x100).

and $3 / 5$ patients had metastasis at the time of diagnosis (Table 1). Although the number of cases reported so far is very low, we observed a tendency to thick tumors and advanced diseases. In our case, the diagnosis of a thick nodular melanoma was incidentally made as well. The clinical scenario of LTS may be particularly challenging leading to a diagnostic delay of melanoma for two main reasons: i) multiple and large seborrheic keratoses may hide the melanocytic neoplasm beneath; and ii) a melanoma may sometimes clinically mimic a seborrheic keratosis. Recently it has been demonstrated that dermatoscopy improves the detection of seborrheic keratosis-like melanomas, increasing significantly the sensitivity. ${ }^{9}$ In our patient, the identification of atypical dermatoscopic features reinforced the clinical diagnosis of melanoma, which was further confirmed by characteristics histopathologic findings.

In conclusion, we highlight that physicians should be aware of the LTS sign for its significant clinical value. Although the association between melanoma and LTS is very rare, an accurate total body skin examination with the aid of dermatoscopy should be recommended in patients with sudden onset or increase in number and size of seborrheic keratoses, in order to early diagnose and treat a melanoma that is hiding among them.

\section{References}

1. Bernett CN, Schmieder GJ. Leser Trelat Sign. Trasure Island (FL): StatPearls; 2020. Available from: http://www.ncbi.nlm.nih.gov/books/NB K470554/

2. Wollina U. Recent advances in manag-

Table 1. Cases reporting an association between melanoma and Leser-Trélat Sign (LTS).

\begin{tabular}{|c|c|c|c|c|c|}
\hline Author & Age, sex & $\begin{array}{l}\text { Primary melanoma } \\
\text { (Breslow thickness and site) }\end{array}$ & $\begin{array}{l}\text { Metastatic } \\
\text { involvement }\end{array}$ & $\begin{array}{l}\text { Leser-Trélat Signn } \\
\text { (site, pattern) }\end{array}$ & Other paraneoplastic signs \\
\hline $\begin{array}{l}\text { Ellis DL et al. } \\
(1987)^{4}\end{array}$ & $\begin{array}{l}454 \text { years } \\
\text { old man }\end{array}$ & $\begin{array}{l}\text { Superficial spreading } \\
\text { melanoma, } 0.75 \mathrm{~mm} \text {, } \\
\text { lower back }\end{array}$ & $\begin{array}{l}\text { No evidence after } 16 \text { months } \\
\text { of follow-up }\end{array}$ & Upper chest and back, & $\begin{array}{l}\text { Acanthosis nigricans, } \\
\text { multiple acrochordons }\end{array}$ \\
\hline $\begin{array}{l}\text { Fanti PA et al. } \\
(1989)^{5}\end{array}$ & $\begin{array}{l}69 \text { years } \\
\text { old man }\end{array}$ & $\begin{array}{l}\text { Nodular melanoma, } \\
2.16 \mathrm{~mm} \text {, left thigh }\end{array}$ & $\begin{array}{l}\text { Regional (inguinal) } \\
\text { lymph nodes }\end{array}$ & $\begin{array}{l}\text { Trunk, thighs, } \\
\text { Christmas tree pattern }\end{array}$ & - \\
\hline $\begin{array}{l}\text { Siedek V et al. } \\
(2009)^{6}\end{array}$ & $\begin{array}{l}82 \text { years } \\
\text { old man }\end{array}$ & Unknown & $\begin{array}{l}\text { Parotid gland, skin } \\
\text { (forehead) and cervical } \\
\text { lymph nodes }\end{array}$ & $\begin{array}{l}\text { Head and trunk, } \\
\text { Christmas tree pattern }\end{array}$ & - \\
\hline $\begin{array}{l}\text { Pereira R. et al. } \\
(2019)^{7}\end{array}$ & $\begin{array}{l}71 \text { years } \\
\text { old } \\
\text { Women }\end{array}$ & Unknown & $\begin{array}{l}\text { Pleura, } \\
\text { lymph nodes (axilla), } \\
\text { skin (?) }\end{array}$ & $\begin{array}{l}\text { Right posterior thoracic region } \\
\text { (zosteriform?) }\end{array}$ & - \\
\hline Our case & $\begin{array}{l}80 \text { years } \\
\text { old women }\end{array}$ & $\begin{array}{l}\text { Superficial spreading } \\
\text { melanoma, } 4,5 \mathrm{~mm} \text {, } \\
\text { right flank }\end{array}$ & $\begin{array}{l}\text { No evidence after } 52 \text { months } \\
\text { of follow up }\end{array}$ & $\begin{array}{l}\text { Trunk } \\
\text { (Christmas tree pattern), } \\
\text { head and neck }\end{array}$ & - \\
\hline
\end{tabular}


ing and understanding seborrheic keratosis. F1000Res 2019;8:F1000 Faculty Rev-1520.

3. Silva JA, Mesquita Kde C, Igreja AC, Lucas IC, Freitas AF, Oliveira SM, Costa IM, Campbell IT. Paraneoplastic cutaneous manifestations: concepts and updates. An Bras Dermatol 2013;88:922.

4. Ellis DL, Kafka SP, Chow JC, et al. Melanoma, growth factors, acanthosis nigricans, the sign of Leser-Trélat, and multiple acrochordons. A possible role for alpha-transforming growth factor in cutaneous paraneoplastic syndromes. $\mathrm{N}$
Engl J Med 1987;317:1582-7.

5. Fanti PA, Metri M, Patrizi A. The sign of Leser-Trélat associated with malignant melanoma. Cutis 1989;44:39-41.

6. Siedek V, Schuh T, Wollenberg A. Leser-Trelat sign in metastasized malignant melanoma. Eur Arch Otorhinolaryngol 2009;266:297-9.

7. Pereira R, Carvalho SD, Cruz JF. LeserTrélat sign in metastatic melanoma to pleura. BMJ Case Rep 2019;12:e228834.

8. Chaudhary S, Bansal C, Husain A. Literature meta-analysis of zosteriform cutaneous metastases from melanoma and a clinico-histopathological report from India. Ecancermedicalscience 2013;7:324.

9. Carrera C, Segura S, Aguilera P, et al. Dermoscopy Improves the Diagnostic Accuracy of Melanomas Clinically Resembling Seborrheic Keratosis: Cross-Sectional Study of the Ability to Detect Seborrheic Keratosis-Like Melanomas by a Group of Dermatologists with Varying Degrees of Experience. Dermatol 2017;233: 471-9. 